\title{
Temperature and sleep
}

\section{Fergus Nicol}

Cass School of Art, Architecture and Design, London Metropolitan University, Calcutta House, London E1 7NT; f.nicol@londonmet.ac.uk

Abstract. Expert guidance in the UK suggests a limit the temperatures in bedrooms to of $26^{\circ} \mathrm{C}$ or less to avoid overheating. This short paper looks at the temperatures in bedrooms and uses data from comfort surveys combined with models which link comfort to the thermal environment. Evidence is given that people sleep comfortably where temperatures are $29-31^{\circ} \mathrm{C}$ in their personal space within the bed and they use bedclothes to allow them to attain these temperatures. The effect of the use of a mattress and the adaptive opportunities afforded by the bedclothes and sleepwear are briefly explored as are methods used in hot climates to offset high bedroom temperatures.

Keywords temperature; sleep quality; comfort; bedclothes and sleepwear; energy.

\section{Introduction}

\section{Acceptable bedroom temperature}

The environmental temperature in the bedroom is known to have an effect on the quality of the sleep which the occupant can expect. One investigation of this is presented in the first chapter of CIBSE Guide A (2015). The researcher (Humphreys 1979) plotted the temperature against the number of blankets (and eiderdown) the subject used (Figure 1). The subjects were living in England and almost all wore pyjamas or a nightdress. Also shown is the quality of sleep the subject experienced (on a five-point scale from good to bad).

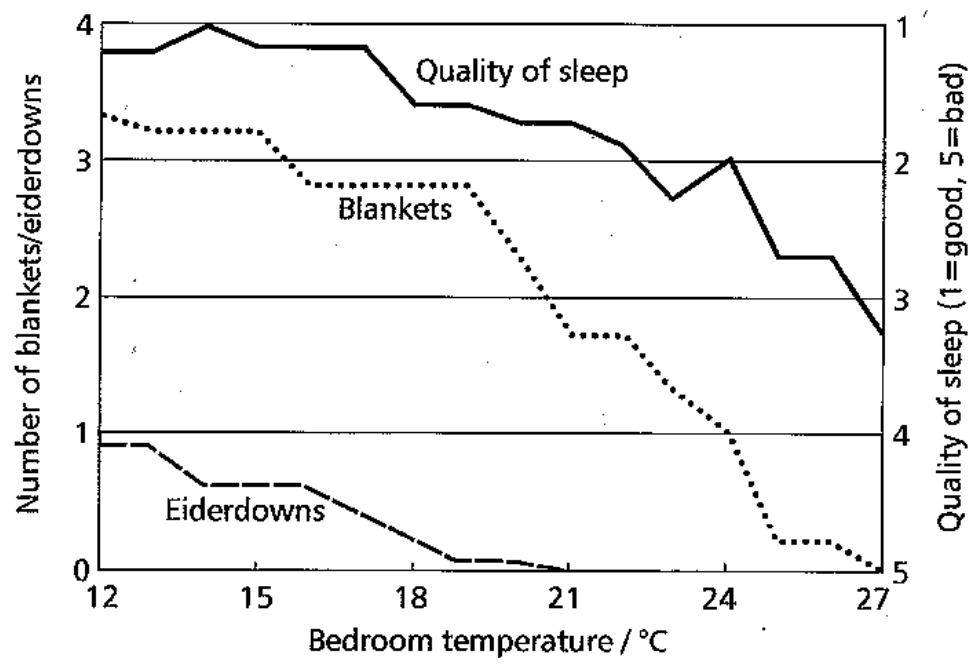

Figure 1. The effect of bedroom temperature upon bedding and quality of sleep (Humphreys 1979)

In the CIBSE (2017) Technical Memorandum TM59, Humphreys' study has been cited amongst others to justify a recommendation to limit temperatures in dwelling bedrooms to less than $26^{\circ} \mathrm{C}$, because it gives some evidence that, in the UK, bedroom temperatures over $26^{\circ} \mathrm{C}$ may be experienced as "bad" for sleep quality, (particularly for those in double beds).

But in view of the likelihood that building designers will resort to financially and environmentally expensive mechanical cooling if they expect the room to be overheated, there is a need to revisit existing literature to ensure that the recommendation will not lead to unnecessarily increased energy use and impacts on occupant's quality of life and the 
environment. Recent advice from the Department of communities and Local Government (DCLG) may further influence designers into following the advice of TM59, so potentially increasing uptake of air-conditioning in UK homes.

Part of the reason for this reconsideration is the changes which have taken place in bedding since much of the historic experimental work was undertaken. Firstly, the accepted bed clothing nowadays is the quilt or duvet, providing different seasonal grades of insulation and/or sheets. Bedclothes now seldom include blankets or eiderdowns ${ }^{1}$. As well as changing the range of insulation available to the sleeper to adapt to bedroom temperature, this change in bedding may have also led to a change in their sleepwear.

Bedrooms are often found in the upper part of the house, and their windows may be kept closed during the day when they are unoccupied, so they could be particularly likely to be hot in summer. But adaptive opportunities such as external shading or shuttering, or improved window opening and security opportunities do not appear in the palette of proposals supplied by CIBSE in their advice to designers. The only solution in their cooling repertoire is a straight move to a mechanical solution, with obvious cost consequences for building owners and users. Getting the correct upper limit for the bedroom temperature is therefore particularly important, as it may also encourage more passive solutions to problems of sleep heat-disturbance with less cost to the owners and the environment

\section{Measurements and modelling of temperature for comfort in bed}

\subsection{Temperature and sleep}

The metabolic rate of a sleeping person is low and as the body prepares for sleep vasodilation occurs which facilitates heat loss and signals a drop in body temperature and a simultaneous increase in the temperature of distal parts such as hands and feet (Krauchi, 2007). In line with this Zhang et al (2018) found that the wrist temperature of sleeping people is $33.8^{\circ} \mathrm{C}-$ some 1.6 degrees higher than during waking hours. As a result changes the temperature regime in the bed becomes an important part of the quality of sleep and the maintenance of body temperature is a part of this.

R K Macpherson (1973) considered the basic requirements of the sleeping person. He quotes an experiment in which the mean temperature close to the body of sleeping subjects was measured and found to be about $28^{\circ} \mathrm{C}$. This is similar to that reported by Mclntyre (1937) (27$29^{\circ} \mathrm{C}$ ) and Haskell $(1981)\left(29^{\circ} \mathrm{C}\right)$. Kingma (Kingma et al 2012 and 2017) and his colleagues of Maastricht University report that the 'thermoneutral zone' of the human body (the band of temperature within which neither sweating nor shivering is necessary) lies between 28 and $32^{\circ} \mathrm{C}$. A temperature of $28-30^{\circ} \mathrm{C}$ under the bedclothes and close to the body suggests the comfortable operative temperature in the room would be one which allows the sleeping person to achieve a temperature of about $29^{\circ} \mathrm{C}$ close to the body. This estimate is in the absence of air movement, as it was taken under the bedclothes close to the subject.

Djongyang (2012) and his co-workers, using a mixture of theory and climate chamber studies, have suggested thermo-neutral operative temperatures in the region of $29-32^{\circ} \mathrm{C}$ for nude subjects in desert climates. They quote a number of papers which have come to the same or a similar sleep temperature for nude subjects. The argument could be advanced that the temperature which people require for comfortable sleep is in the region of $30^{\circ} \mathrm{C}$. The

\footnotetext{
${ }^{1}$ The duvet is a soft quilt filled with down, feathers or synthetic fibre used instead of blankets, an eiderdown is like the duvet but smaller, used as an addition to the blankets in cold weather
} 
function of the bedclothes and sleepwear is to provide a microclimate at that temperature in the vicinity of the skin surface when they are asleep.

Lan et al (2014) measured sleep quality for subjects in a climate chamber and wearing light sleepwear and a blanket, at three temperatures: $23^{\circ} \mathrm{C}, 26^{\circ} \mathrm{C}$ and $30^{\circ} \mathrm{C}$ and found that proportion of subjects reporting 'sufficient sleep' at $26^{\circ} \mathrm{C}$, was greater that at either $23^{\circ} \mathrm{C}$ or $30^{\circ} \mathrm{C}$. In addition $26^{\circ} \mathrm{C}$ was less likely to cause thermal discomfort either before or during the sleep period.

Obradocich et al (2017) showed that human sleep loss is also affected by the weather, in that greater sleep loss is indicated when the outdoor temperature is hotter than normal for the time of year.

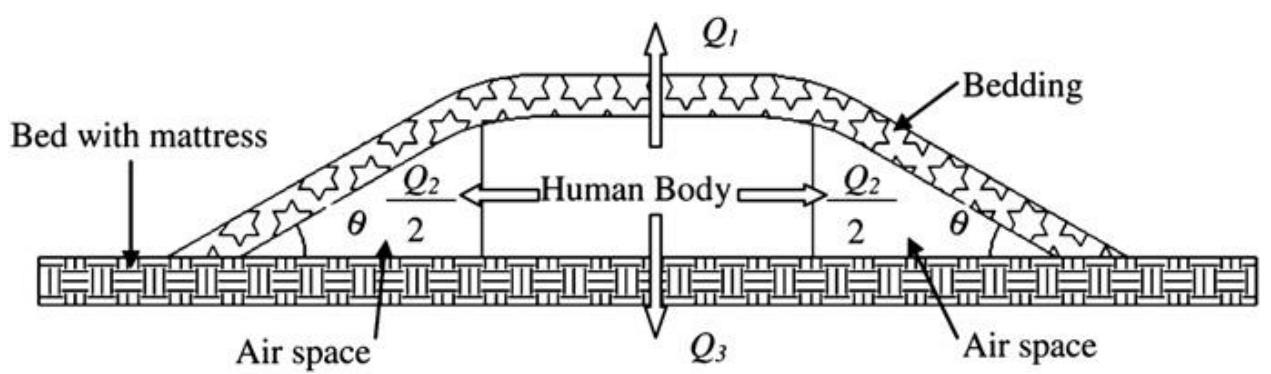

Figure 2. Schematic of heat transfer pathways in a bedding system including a sleeping occupant (from Pan et al 2010)

\subsection{Heat balance for sleeping people}

There is some complexity in the thermal pathways to the room environment from the body beneath the bedclothes and the sleepwear. Heat is lost in many directions and through different combinations of coverings: downwards through the sleepwear, sheet and mattress; upwards through the sleepwear sheet and blankets or duvet, and sideways into the air around the body, and maybe movements of the body allow air to escape or enter the 'capsule' of air surrounding the sleeper. In addition there is the heat loss directly from the uncovered parts of the body such as the face and limbs exposed during sleep. In addition heat is also lost through respiration and sweating. A useful model of the heat loss pathways is given by Pan et al (2010) · (Figure 2)

There is an additional complication when the subject is in a bed with the highly insulated sprung mattress as used in many countries. In summer, when the clothing above is light, the body is losing heat almost entirely through that part which is not in contact with the mattress. This is physically equivalent to increasing the metabolic rate by about $20 \%$ because the proportion which is in contact with the mattress is about $20 \%$ of the area of the whole body (Pan et al 2010, Raja and Nicol 1997).

\section{Room temperature for comfort in physiological models}

\subsection{Physiological models}

Humphreys' simple 1970 model of the thermal relationship between clothing, metabolic rate and operative temperature is illustrated in Figure 3a. The ASHRAE standard 55 suggests that the metabolic rate for a sleeping person is about $41 \mathrm{wm}^{-1}$. This (approximate) model suggests that the temperature comfort zone in still air is $30-32^{\circ} \mathrm{C}$ and with the increase in the effective metabolic rate to about $50 \mathrm{wm}^{-2}$ to allow for a mattress it is $29-31^{\circ} \mathrm{C}$. The maximum comfort temperature for the sleeping unclothed body (above which an increase is required in sweat rate to maintain the thermal equilibrium) is therefore about $32^{\circ} \mathrm{C}-$ or $31^{\circ} \mathrm{C}$ with allowance for a mattress(from Humphreys et al (2016) chapter 20). A development of Humphreys' diagram 
(Figure $3 \mathrm{~b}$ ) suggests these maximum temperatures can be increased to $34^{\circ} \mathrm{C}\left(33^{\circ} \mathrm{C}\right.$ with mattress) if the air speed is increased to $1 \mathrm{~m} / \mathrm{s}$.
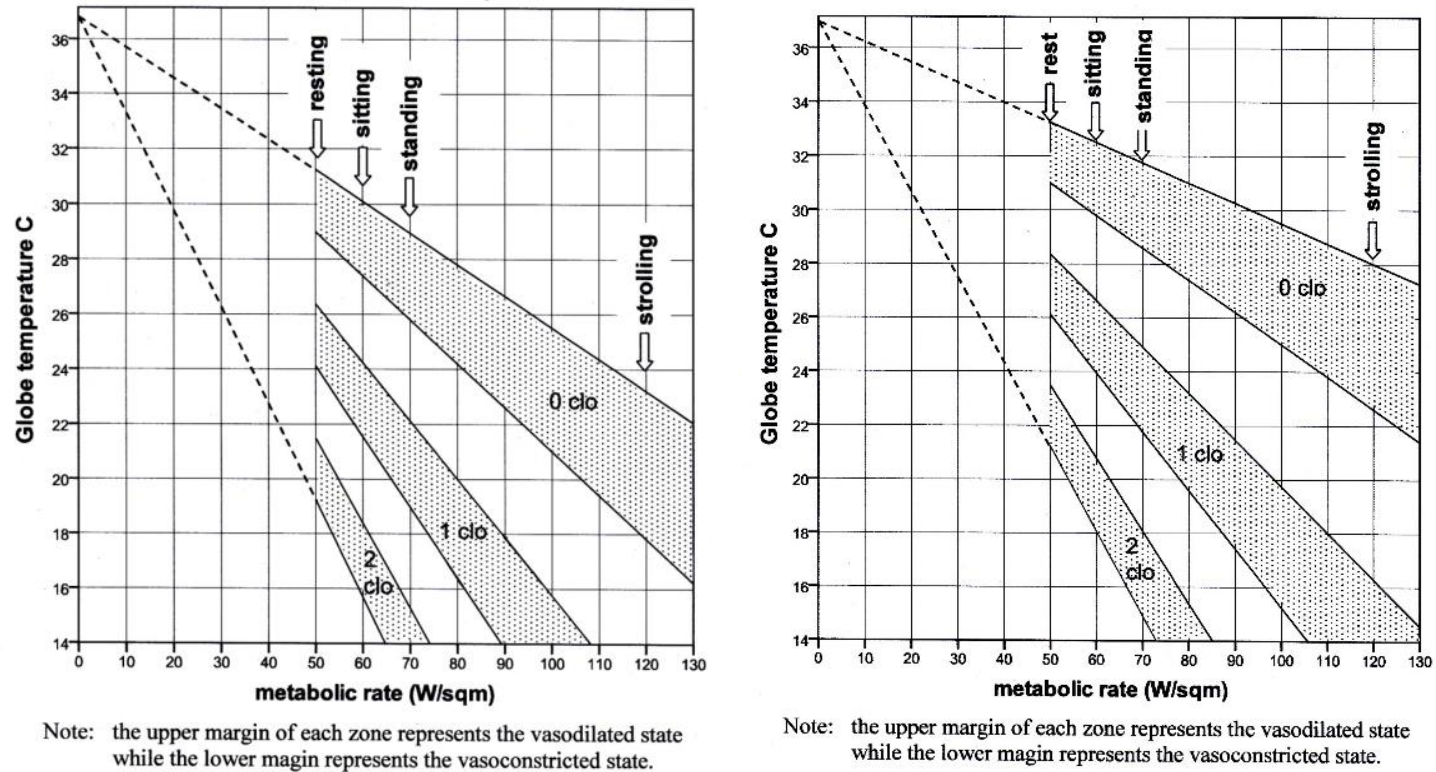

Figure 3, Humphreys 1979 schematic diagram of comfort zones various levels of clothing. The diagram on the left (a) is for still air and on the right (b) for air speed of $1 \mathrm{~m} / \mathrm{s}$ (from Humphreys et al 2016 chapter 20)

The optimum (PMV = 0) sleeping temperature is predicted by Fanger's (1972) PMV index for nude people at minimal metabolic rate and no bedclothes or sleepwear covering is $31^{\circ} \mathrm{C}$. Fanger also gives a comfort temperature of $34^{\circ} \mathrm{C}$ for air speed of $1 \mathrm{~m} / \mathrm{s}$. To allow for a mattress we can increase the metabolic rate by $20 \%$ from 0.7 met to 0,85 met; then the temperature at which there is a balance between heat production and heat loss is reduced to $30^{\circ} \mathrm{C}$. The upper temperature limit to avoid heat discomfort (i.e. $\mathrm{PMV}=0.5$ ) is $31.5^{\circ} \mathrm{C}$ or $30.5^{\circ} \mathrm{C}$ with mattress. These temperatures can again be increased by about 2-3K by an increase in air speed to $1 \mathrm{~m} / \mathrm{s}^{2}$.

This analysis suggests that the maximum comfort temperature for nude sleeping people is about $4-6 \mathrm{~K}$ above the $26^{\circ} \mathrm{C}$ suggested by TM59. The low values of temperature suggested by Humphreys in 1979 may be explained by the sleeping habits of the UK subjects. It is not recorded what night clothes the subjects were wearing but some sort of light sleepwear was the norm at the time of the surveys, added to which a light cotton sheet would have been normal, bringing the equivalent clothing insulation up to approximately $0.4-0.6 \mathrm{Clo}$. Using Fanger's PMV this set-up would give a sleeping comfort temperature of about $30.5^{\circ} \mathrm{C}$, and the temperature-limit for $(P M V=+0.5)$ would have been $31.5^{\circ} \mathrm{C}$. Using the Humphreys diagram would suggest a comfort temperature of $29^{\circ} \mathrm{C}$ and an upper limit of $31^{\circ} \mathrm{C}$

There is a popular conception that humidity plays an important role in the thermal comfort of people. In terms of the thermal sensation of the subjects the thermal comfort of the individuals as measured in comfort surveys (Humphreys et al $2016 \mathrm{pp} 179,180$ ) is small if a direct measurement such as the water vapour in the atmosphere is used. If humidity is measured as relative humidity it may appear important but that is because $\mathrm{RH}$ incorporates temperature in its definition, and this is reflected in the statistics. At the temperatures we are

\footnotetext{
${ }^{2}$ All estimates in these PMV calculations use the Berkeley 'CBE Thermal Comfort Tool' which is available on the internet at http://comfort.cbe.berkeley.edu
} 
assuming within a bed (say $30^{\circ} \mathrm{C}$ ) the difference between $0 \mathrm{kPa}$ (zero humidity) and $4 \mathrm{kPa}$ (about the maximum for air at this temperature) the difference in PMV is about 1 . In reality the inside of an occupied bed is unlikely to have anything like this range of humidity.

\subsection{Bedclothes}

Bedclothes such as sheets and blankets and duvets have an important function in making the bed occupants comfortable and safe.

The thermal insulation of bedclothes is measured in Togs which roughly translate to the more familiar clo units according to the ratio 1 clo $\approx 1.55$ tog. Commonly a summer duvet is about 3 Tog (about 2 clo) and a winter duvet about 9 Tog (about 6 clo). The Humphreys model suggests that, in the resting metabolic rate, each clo of insulation reduces the comfort temperature by about $5 \mathrm{~K}$ ignoring the mattress or $6 \mathrm{~K}$ including the mattress. This suggests that the summer duvet is appropriate at bedroom temperatures of around $21.5^{\circ} \mathrm{C}$ without a mattress or $18^{\circ} \mathrm{C}$ with a mattress. The winter duvet should provide comfort down to just above $0^{\circ} \mathrm{C}$, or even lower in combination with a highly insulating mattress and/or underblanket.

\subsection{Adaptive actions}

The way in which a duvet is used can be very adaptive. They are not normally 'tucked in' under the mattress as were blankets and this allows the users to move themselves around and adjust the bedclothes to their personal needs (Figure 4) During cold conditions this could be a problem if cold air from the room infiltrates or the exposed parts of the body get too cold, so the above calculated values of the comfort temperature with a winter duvet may be too low. However, in a cold room many will tend to sleep curled up, with the limbs and even the head under the cover of the duvet. Air movement is another adaptive opportunity as suggested by Lan et al (2013) in a study of personal ventilation.

The success of the adaptive use of bedclothes is indirectly illustrated by the finding by Imagawa et al (2015a) following a survey in 25 houses in Japan. From an analysis of over 3000 assessments of the effect of temperature on sleep in bedrooms with indoor air temperatures between $21-34^{\circ} \mathrm{C}$ Imagawa and Rijal (2015b) that "there was no distinctive relationship between the depth of sleep reported by the subjective vote and indoor air temperature".

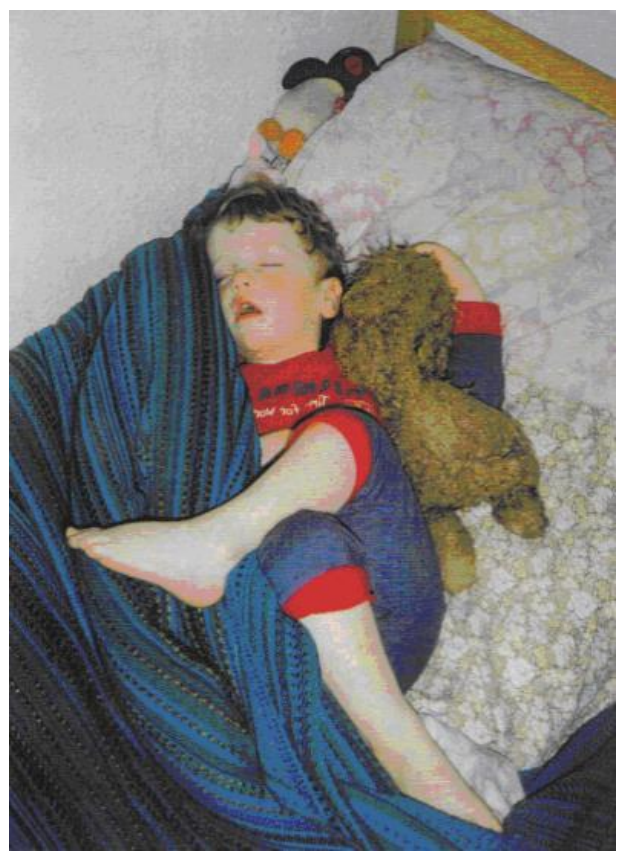


Figure 4 illustrating the ability of a young duvet user to adjust his posture and bedclothes to suit his needs (from Nicol et al 2012, photograph by R. H. Roberts)

\subsection{Posture in bed}

Another common response to discomfort in bed is to adjust posture. Most of the experimental evidence for comfort in bed (e.g. Zhang et al) measures bedding insulation using mannikins in a prone position. Many people sleep in what can be characterised as a Foetal position (curled up like a baby). In a standing person a change of posture can reduce the effective surface area of the body by as much a 30\% (Raja and Nicol, 1997). In bed the heat flow paths are less defined and the warming effect of curling up less clear. A smaller area will be warmed by the bed occupant as the legs are drawn up in the bed and this will result in a smaller heat loss if the inner temperature of the bed is almost constant, at the same time within the bed many body parts are not in contact with the bedclothes (which are the heat sink) but in effect with each other, reducing heat loss. Over all the effect of postural changes of this sort will be to reduce heat loss, potentially improving comfort for those who are cold.

\section{Sleeping in hot climates}

In hot climates there are several ways in which people avoid the problem of being too hot in bed without the use of mechanical cooling. Some are listed below:

- $\quad$ using a bed without the insulated mattress (for example using a string mattress)

- $\quad$ using a fan to provide air movement

- $\quad$ wrapping themselves in a 'sleeping cloth' which in hot conditions will become wet and thereby reducing its insulation and at the same time spreading the sweat and so increasing evaporation, and preventing disturbance from sweat running down the skin

- $\quad$ moving to another place (for instance on to the roof to take advantage of radiant cooling to the sky) or into a cool basement

Sekhar and Goh (2011) suggest that in a hot-humid climate a mechanically ventilated bedroom has a wider and hotter range of acceptable temperatures $\left(27-30.5^{\circ} \mathrm{C}\right)$ than one with air conditioning $\left(22.5-25.5^{\circ} \mathrm{C}\right)$ and ascribe the difference, at least in part, to the greater level of personal control which they have over the indoor conditions. Lin and Deng (2006) found that $80 \%$ of their respondents in air conditioned apartments preferred a room temperature below $24^{\circ} \mathrm{C}$ and Yang and Olofsson (2017) got a similar result in Singapore.

\section{Discussion}

This short paper suggests that a model of the dependence of comfort and sleep quality on bedroom temperature could start with the observation suggested by a number of researchers that the temperature of the immediate microclimate around the sleeper should be around $29-32^{\circ} \mathrm{C}$. This finding is strengthened by the use of two thermal models of the human body (Humphreys and PMV) which suggest a similar comfort temperature for nude sleeping subjects in the absence of air movement. The role of sleepwear and bedclothes is to allow the sleeping person to adapt to the temperature in the bedroom. This is primarily a behavioural adaption of the person to the conditions in the bedroom. Other adaptive responses would be to modify the temperature in the room using heating or cooling devices or passive means as 
are suggested (for hot conditions) in the bullet points in section 2.1 above. The desirability of further research of the microclimate in the bed and its relationship to bedroom temperature is indicated.

\section{Conclusions}

There have been a number of attempts to gauge the thermal comfort of sleeping people but this is a difficult endeavour. In the first place the normal field survey relies on the ability of the researcher to ask a subjective question, and the ability of the subject to give an answer. I addition there are problems with the measurement of such important facts as clothing resistance and posture of the subject, which may vary in an unpredictable way.

This paper seeks use a mixture of physiological modelling and adaptive theory to look at the acceptable temperature within bedrooms as the product of the provision of comfort within the bed. Accepting that the sleeping occupants will have a constant body temperature and a fixed metabolic rate it is possible to calculate the level of insulation which will required. The findings are:

- The temperature of the immediate space around a sleeping person should be about $30^{\circ} \mathrm{C}$ to ensure access to comfort and adequate sleep.

- The purpose of the bedding is to allow the sleeping person to achieve this temperature in their immediate personal space within the bed.

- The maximum temperature in bedrooms to avoid discomfort and sleep loss is therefore a function of the bedroom environment (temperature and air movement) and the available adaptive opportunities including passive or mechanical heating or cooling, sleepwear and bedding.

- The use of a well-insulated mattress will lower the room temperature the occupant will find comfortable.

- Bedroom occupants will use bedding as an adaptive opportunity at temperatures which would otherwise make sleep difficult

\section{References}

CBE Thermal Comfort Tool (http://comfort.cbe.berkeley.edu/).

CIBSE, 2015. CIBSE Guide A, Environmental Design Chapter 1: Environmental Criteria for Design, London, Chartered Institution of Building Services Engineers

CIBSE, 2017. TM59 Design methodology for the assessment of overheating risk in homes. London, Chartered Institution of Building Services Engineers

Djongyang, N, Tchinda, R and Njomo, D, 2012. Estimation of some comfort parameters for sleeping environments in dry-tropical sub-Saharan Africa region, Energy conversion and management, 58 110-119

Fanger, PO, 1970. Thermal Comfort New York, McGraw Hill

Haskell, EH, Palca, JW, Walker, JM, Berger, HJ and Heler HC, 1981. Metabolism and thermoregulation during stages of sleep in humans exposed to heat and cold Journal of Applied physiology Respiratory Environmental and Exercise Physiology, 51948

Humphreys, M A, 1979. The influence of season and ambient temperature on human clothing behaviour Proc International Climate Symposium, Copenhagen, September 1978

Humphreys, MA, 1970. A simple theoretical derivation of thermal comfort conditions. Journal of the Institution of heating and ventilating Engineers, 38, 95-98

Humphreys, MA, Nicol, JF, and Roaf, SC, 2016. Adaptive Thermal Comfort, Foundations and Analysis, London, Routledge. (Chapter 20 pp 182-19)

Imagawa, H., Rijal, HB., and Shukuya, M., 2015a. Field survey on the comfort temperature and occupant behaviour in bedrooms (in Japanese) 
Imagawa H., Rijal HB., 2015b. Field Survey of the thermal comfort, quality of sleep and typical occupant behaviour in the bedrooms of Japanese houses during the hot and humid season. Architectural Science Review, 58(1) 11-23

Kingma, B. R., Frijns, A., and van Marken Lichtenbelt, W. D., 2012. The thermoneutral zone: implications for metabolic studies. Frontiers in Bioscience, Elite edition, E4, 1975-1985. DOI: 10.2741/e51

Kingma, B., Schweiker,M., Wagner, A. and van Marken Lichtenbelt, W. 2017 Exploring a biophysiological model to understand thermal sensation, Building Research and Information vol. 45(7)

Krauchi, K, 2007. The thermophysiological cascade leading to sleep initiation in relation to phase of entrainment. Sleep Med. Rev. 11 439-451

Lan, L., Pan, L., Lian, Z., Huang, H. and Lin, Y., 2014. Experimental study of thermal comfort of sleeping people at different air temperatures, Building and Environment, 73, 24-31

Lan, L., Lian, Z., Zhou, X., Sun, C., Huang, H., Lin, Y. and Zhou, Y. 2013. Pilot study on the application of bedside personalized ventilation to sleeping people, Building and Environment 67 150-166

Lin ZP and Deng SM. A questionnaire survey on sleeping thermal environment and bedroom air conditioning in high-rise residences in Hong Kong. Energy and Buildings 2006; 38: 1302-1307.

Macpherson, RK, 1973. Thermal stress and thermal comfort, Ergonomics 16(5) 611-622

McIntyre, J, 1937. Discussion of the effect of water vapour content... JIHVE 4, 570-601

Nicol, JF, Humphreys, MA and Roaf, SC, 2012. Adaptive thermal comfort: Principles and Practice, London, Routledge

Obradovich, N., Migliorini, R, Mednick, S. and Fowler, J, 2017. Nightime temperature and human sleep loss in a changing climate Science Advances 3 e.1601555

Pan, D, Lin Z and Deng, S, 2010. A mathematical model for predicting the total insulation value of a bedding system, Building and Environment 45 1866-1872

Raja, I.A. and Nicol, J.F., 1997. A technique for postural recording and analysis for thermal comfort research Applied Ergonomics 28 (3) pp. 221-225

Sekhar SC and Goh SE. Thermal comfort and IAQ characteristics of naturally/mechanically ventilated and airconditioned bedrooms in a hot and humid climate. Building and Environment 2011; 46: 1905-1916

Yang B and Olofsson T. A questionnaire survey on sleep environment conditioned by different cooling modes in multistorey residential buildings of Singapore. Indoor and Built Environment 2017; 26(1): 21-31.

Zhang, N. Cao, B and Zhu, Y (2018) A research on the effects of indoor environment on sleep quality. Proceedings of the $10^{\text {th }}$ Windsor Conference "Rethinking Comfort". Network for Comfort and Energy Use in Buildings http://nceub.org.uk 